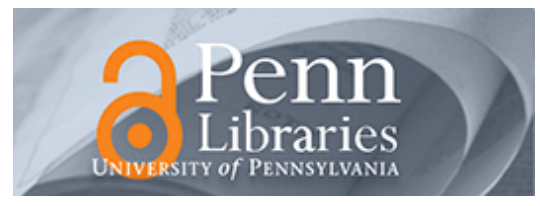

University of Pennsylvania ScholarlyCommons

$4-1-2010$

\title{
Intimate Partner Violence at the Scene: Incident Characteristics and Implications for Public Health Surveillance
}

Manisha Joshi

Susan B. Sorenson

University of Pennsylvania, sorenson@sp2.upenn.edu

Follow this and additional works at: https://repository.upenn.edu/spp_papers

Part of the Public Affairs, Public Policy and Public Administration Commons

\section{Recommended Citation}

Joshi, M., \& Sorenson, S. B. (2010). Intimate Partner Violence at the Scene: Incident Characteristics and Implications for Public Health Surveillance. Retrieved from https://repository.upenn.edu/spp_papers/157

Postprint version.

Joshi, M., \& Sorenson, S. B. (2010). Intimate partner violence at the scene: Incident characteristics and implications for public health surveillance. Evaluation Review, 34(2), 116-136. doi: 10.1177/0193841X09360323

The final published version of this article can be found online at:

http://erx.sagepub.com/content/34/2/116

This paper is posted at ScholarlyCommons. https://repository.upenn.edu/spp_papers/157

For more information, please contact repository@pobox.upenn.edu. 


\title{
Intimate Partner Violence at the Scene: Incident Characteristics and Implications for Public Health Surveillance
}

\author{
Abstract \\ Using data that, to our knowledge, have not been used before for this purpose, we examined 9,231 \\ opposite-sex intimate partner violence calls for law enforcement assistance recorded in the Compstat \\ system of a large U.S. city. Although women were the predominant victims, injuries were documented \\ more often for men. Only about $1 \%$ of incidents were considered to be a restraining order violation \\ although many orders were active in the city at the time. The data appeared to be of good quality and just \\ a few changes in recording procedures would increase Compstat's usefulness for public health in U.S. \\ cities.
}

\section{Keywords}

intimate partner violence, Compstat system, police, law enforcement, injury

\section{Disciplines}

Public Affairs, Public Policy and Public Administration I Social and Behavioral Sciences

\section{Comments}

Postprint version.

Joshi, M., \& Sorenson, S. B. (2010). Intimate partner violence at the scene: Incident characteristics and implications for public health surveillance. Evaluation Review, 34(2), 116-136. doi: 10.1177/ $0193841 \times 09360323$

The final published version of this article can be found online at:

http://erx.sagepub.com/content/34/2/116 


\title{
Intimate Partner Violence at the Scene:
}

\section{Incident Characteristics and Implications for Public Health Surveillance}

\author{
Manisha Joshi* and Susan B. Sorenson \\ School of Social Policy and Practice \\ University of Pennsylvania \\ Philadelphia \\ USA
}

*Corresponding author

School of Social Policy \& Practice, University of Pennsylvania

3815 Walnut Street, Philadelphia, PA 19104

Email: manishaj@sp2.upenn.edu

Phone: 215-573-9769

Fax: 215-573-2791

Acknowledgements: We thank Richard A. Berk for making these data available and Katherine A.Vittes for helping with data management. 


\begin{abstract}
Using data that, to our knowledge, have not been used before for this purpose, we examined 9231 opposite-sex intimate partner violence calls for law enforcement assistance recorded in the Compstat system of a large U.S. city. Although women were the predominant victims, injuries were documented more often for men. Only about $1 \%$ of incidents were considered to be a restraining order violation although many orders were active in the city at the time. The data appeared to be of good quality and just a few changes in recording procedures would increase Compstat's usefulness for public health in U.S. cities.
\end{abstract}

\title{
Key words
}

intimate partner violence, Compstat system, police, law enforcement, injury 


\section{Intimate Partner Violence at the Scene: Incident Characteristics and Implications for Public Health Surveillance}

More than one million non-fatal cases of intimate partner violence (IPV) occur in the United States each year (Rennison and Welchans 2000). Among opposite-sex couples who experience at least one IPV incident in the previous year, $40 \%$ of the incidents involve kicking, punching, strangling, or stabbing (Straus and Gelles 1999). Although most incidents of intimate partner victimizations are not reported to the police (Tjaden and Thoennes 2000), many victims have called the police (Bachman and Saltzman 1995; Brookoff et al. 1997; Chaudhuri and Daly 1992; Hutchison and Hirschel 1998), many multiple times (Houry et al. 2004).

Police often are the first responders in IPV cases, and yet, relatively little is known about non-fatal IPV that comes to their attention. Police data on IPV can be useful in many ways. First, it can help identify high risk groups that can be targeted through prevention strategies. Second, it can inform the development of critical interventions, changes in existing policies, and expansion of services. And, third, the information gathered from law enforcement can help other sectors. For example, police-attended IPV victims are more likely to have experienced severe abuse, injury or harm that requires medical care (Bonomi et al. 2006; Davies, Block, and Campbell 2007; Kothari and Rhodes 2006) and, as such, law enforcement information is relevant to health care providers and systems.

In addition, the routinely collected police data on crime, including IPV incidents, may be a useful resource for public health surveillance. In fact, in many communities, police incident reports may be the only source of ongoing, routinely collected information about victimization by intimate partners (Saltzman, Mercy, and Rhodes 1992). The data used in the present study 
come from a police data system that has been adopted by many U.S. cities and prove useful for metropolitan locales across the nation.

The primary objectives of this study were twofold: 1) to describe the nature and characteristics of opposite-sex IPV that comes to the attention of the police (e.g., when calls occurred, types of assaults, types of weapons used, severity levels of violence), and to assess for gender differences, and 2) to explore the utility of law enforcement data for public health surveillance. This investigation contributes to the IPV literature by examining data that, to our knowledge, have not previously been reported in the peer-reviewed literature - police incident reports filed through the Compstat system, an innovative management and technological system used by law enforcement authorities in several large U.S. cities (Willis, Mastrofski, and Weisburd 2007).

In the following sections we will present the study findings, discuss the results, and then address implications for practice.

\section{METHODS}

\section{Study Design}

We conducted a secondary analysis of police incident reports available through the Compstat database of the law enforcement department in the study setting. This descriptive research study was granted approval by the Institutional Review Board of University of Pennsylvania.

\section{Data Source}

Data were drawn from the Compstat system of a large U.S. city. Compstat, an organizational and 
administrative system introduced in 1994 by the New York City Police Department (Willis, Mastrofski, and Weisburd 2003), has been adopted by multiple metropolitan locales. This information-driven system emphasizes the collection, analysis and mapping of crime data and other police performance measures on a regular basis to increase an agency's capacity to reduce crime and hold police managers accountable for their performance (Bratton and Malinowski 2008; Philadelphia Police Department n.d.; Shane 2004; Willis, Mastrofski, and Weisburd 2007).

Compstat database consists of information from incident reports filed by police officers in response to service calls (i.e., 9-1-1 calls) or incidents that officers themselves witness in the field. The information from the incident reports (e.g., details on victim, suspect, and type of incident) is entered in the computerized database in the form of data codes. In addition, if a narrative account of the incident is provided by the officer, it is recorded in the database; in a truncated manner (only the first 80 characters of the narrative are recorded). Compstat systems in different locales use different methods (e.g., crosschecking, double-checking) to assure the accuracy of data entered in the database (Willis, Mastrofski, and Weisburd 2003).

\section{Study Population}

We reviewed non-fatal IPV reports involving adult victims (18 or more years old) from a total of 390449 incident reports filed during January through September 2005 . A total of 10175 incidents were identified and charged as spousal/cohabitant simple or aggravated assault (crime class code). We identified an additional 1018 incidents including crime class codes like - rape, attempted rape, assault with a deadly weapon, criminal threat, threatening letter or phone call, restraining order or court order violation, vandalism, and so on - with spouse or cohabitant suspects that were not labeled as spousal/cohabitant abuse. 
In preparation for analysis, each of the 11193 possible IPV incidents was reviewed and considered for inclusion using a systematic criterion. An incident was classified as IPV if it fulfilled any of the following: 1) the crime class was listed as spousal/cohabitant aggravated assault or simple assault, as long as the victim-suspect age difference was less than 15 years (to exclude assaults by a parent or guardian), and the narrative did not convey contradictory information (e.g., "victim was the mother of the suspect") 2) the relationship code identified the suspect as an intimate partner, as long as the narrative did not say otherwise and 3) the narrative identified the relationship as intimate (e.g., boyfriend/girlfriend, ex-boyfriend/ex-girlfriend).

We used narratives (i.e., the first 80 characters of an officer's written description of an incident) to supplement existing Compstat codes and to identify information not otherwise captured by the available codes. A narrative was recorded for almost three-fourths $(73.3 \%)$ of the incidents; male and female victims were about equally likely to have a narrative $(76.5 \%$ vs. 72.7\%). The narratives were searched for information on victim-suspect relationship (e.g., spouse or cohabitant) and specific assaultive acts (e.g., choke, stab, bite) that should have been included in a preexisting Compstat code but was missing and included therein.

In addition, the narratives were searched for words such as separated, divorced, child-incommon, boyfriend/ex-boyfriend, and girlfriend/ex-girlfriend, to gather more information on the victim-suspect relationship, and new codes were developed. Additional variables were also created to capture the nature and characteristics of assaultive acts committed against partners (e.g., assaults to the face or head, number of different types of assaults, observed injury).

Incidents with incomplete information that made it difficult to determine whether the incident was IPV-related or incidents that could not be IPV (e.g., crime class of assault by a spouse or cohabitant, but the narrative indicated the suspect is the victim's father) were not 
included ( $\mathrm{n}=1015)$. Incidents that did not have suspect information $(\mathrm{n}=340)$, or had multiple suspects $(=173)$ were also excluded. Also, incidents that involved same sex couples $(n=434)$ were excluded to allow for more direct comparison to prior research, which generally focuses on opposite- or same-sex IPV. Thus, the remaining incidents $(\mathrm{N}=9231)$ formed the basis of our analysis. Most (90.9\%) of the cases were identified as those that were charged as simple or aggravated assault by a spouse or cohabitant; an additional 836 incidents were identified from crimes not labeled as spousal/cohabitant aggravated or simple assault, but that involved a spouse or opposite-sex cohabitant as the suspect.

\section{Data Management and Analysis}

Descriptive statistics were calculated to examine victim, suspect, and incident characteristics separately for male and female victims. U.S. census data from the same time period were used to calculate rate estimates for annual risk of police-documented IPV in the city in which the data were gathered (American Community Survey 2005). Tests of statistical inference were not indicated given that the study data were based on all, not a sample of, cases that occurred in the city.

\section{Results}

\section{Demographic and Relationship Characteristics}

Rates of victimization by an intimate partner were higher for women than men (see Figure 1). And, following patterns observed in other crimes involving personal violence, the risk of policeattended IPV was highest for non-Hispanic Blacks, followed by Hispanics, non-Hispanic Whites, 
Asians and Asian Pacific Islanders.

Women were disproportionately the victims of IPV, representing $85.6 \%$ of the victims. Most of the couples, whether involving a female or a male victim, were of the same ethnic group (see Table 1). The median age was 30 years for female victims and 35 years for men. Although most female victims were younger than and male victims were older than their suspected assailants, $13.4 \%$ of the female victims had a suspect who was five or more years younger and $10.6 \%$ of the male victims had a suspect who was five or more years older.

The distribution of relationship type was similar for female and male suspects. Regardless of gender, the victim-suspect relationship was not specified in two thirds of the incidents; when specified, the most common relationship was married (73.3\%) or dating $(21.0 \%)$. About $5.7 \%$ of the victims formerly had a relationship with the suspected assailant. Slightly under one third of the victims, regardless of gender $(31.3 \%$ of female and $32.9 \%$ of male victims), were living with the suspect. One in twelve $(8.8 \%)$ of the victims $(8.6 \%$ of the women and $9.8 \%$ of the men) had a child with the suspect.

\section{Incident Characteristics}

Number of IPV calls. On an average day, 34 IPV (29 female and 5 male) victimizations were reported to the police. There was a weekly rhythm with more IPV incidents occurring on weekends. A majority of the incidents (56\%) occurred between 6 p.m. and 4 a.m. Also, compared to the daily average, the number of incidents reported was higher on holidays: New Year's Day: 56; Memorial Day: 53; Independence Day: 55; and Labor Day: 46. The number of IPV incidents during Valentine's Day ( $n=23)$ was significantly below the daily average. The 
study period did not include two other major holidays, Christmas and Thanksgiving.

Weapons used. Violence using personal weapons (hands, fists or feet) was common (see Table 2). Gender differences were observed in the use of an external object: Male victims were more likely than female victims to be attacked or threatened with a cutting or stabbing instrument, blunt object or a household item. Although firearms were used in less than $1 \%$ of the incidents for both genders, 64 out of the 71 victims were women. In three of the 71 incidents, the victims were shot and all these victims were women. In 40 of the 60 incidents that involved a firearm and for which the narratives provided information, the firearm was used to threaten the victim (e.g., "susp(ect) points gun at vic(tim’s) head susp(ect) pulls the trigger in attempt to scare $\operatorname{vic}(\operatorname{tim}) ")$.

Nature and characteristics of assaultive acts. A wide range of assaultive acts came to the attention of the police. Female and male victims were almost equally likely to be struck by their partners. Violent behaviors like punching, strangling, knocking to the ground, pushing, kicking, and arm twisting, were more commonly used by men, whereas women were more likely to bite, scratch, and use an external weapon. A higher proportion of female than male victims $(10.7 \%$ vs. 3.6\%) were intimidated, threatened to be killed, or victimized in some other way (e.g., handcuffed, blindfolded).

Among the $73 \%$ of incidents that had a narrative report, female victims were twice as likely as men (14.9\% vs. $8.1 \%)$ to have been attacked on the face or head. Female victims were $58 \%$ more likely than male victims to be attacked repeatedly with one type of assaultive behavior (e.g., kicked repeatedly). Women were twice as likely as men (15.6\% vs. $7.6 \%)$ to experience 
two types of assaultive behaviors (e.g., punched and kicked) and ten times more likely to experience three or more types of assaultive behaviors (5.3\% vs. 0.5\%). Although incident characteristics suggest that a substantial proportion of women victims experienced severe violence, the proportion of victims with police observed injuries was twice as high for male than female victims $(22.9 \%$ vs. $11.4 \%)$.

Overall, assaultive behaviors against women seemed to be more severe than those against men. Nevertheless, a majority of behaviors whether involving a female or a male victim had the potential for causing injury (78.8\% and $64.9 \%$, respectively).

A substantial minority of incidents, even when taking into account the narratives, did not specify the assaultive behavior (38.7\% of those with female victims and $45.5 \%$ of those with male victims). Moreover, the narratives were not long enough to yield such information for all incidents.

Charges and case status. On average, there was one charge per incident, most often spousal/cohabitant simple assault $(83.9 \%$ of those involving female victims and $82.3 \%$ involving male victims). A total of $9.3 \%$ of the incidents involving male victims and $7.1 \%$ of those involving female victims were considered serious enough to merit an aggravated assault charge (i.e., victim seriously injured or weapon used). Other charges included assault with a deadly weapon, rape, battery misdemeanor, criminal threats, and threats by letter or phone call. Very few incidents were specifically charged with the violation of a restraining order, temporary restraining order or a court order $(0.7 \%$ for female victims and $1.1 \%$ for male victims $)$. The remaining victimizations involved charges such as vandalizing property, stealing money, brandishing a weapon, or a general domestic violence charge that also included some temporary 
restraining order violations ( $11.4 \%$ for female victims, $8.4 \%$ for male victims). Given that temporary restraining orders were included in this latter, general category, it was not possible to estimate the total number of temporary restraining order violations.

A substantial majority of the cases (64.8\% of female victims, $73.7 \%$ of male victims) were cleared (either by arrest or other means) immediately. About one third of the cases involving female and one fourth of those involving male victims remained under investigation. None of the IPV calls for assistance were labeled as "report unfounded" at the time the incident report was filed.

\section{Discussion}

Many IPV-related calls were received each day by the city law enforcement department. Our findings support previous research documenting that IPV calls may be the single largest group of calls to the police (Friday et al. 2006; Klein 2009). In some locales, the numbers may be so high as to comprise more than one half of all calls for service (Klein 2009). Given that so many IPV victims seek help from the police (Friday et al. 2006; Hutchison and Hirschel 1998), and that many do so repeatedly (Friday et al. 2006; Houry et al. 2004), it is important that agencies focus and dedicate as much time and resources to IPV as they do to other major crimes (Klein 2009).

Similar to findings from previous research and what experienced police officers have learned, we found that a majority of IPV incidents occurred in between the evening and early morning hours (Catalano 2006; Johnson 2007), on weekends (Johnson 2007; Shepherd 1990) and on major American holidays (Rotten and Frey 1985). It is possible that a higher likelihood of partners being together on weekends or holidays, and/or increased alcohol consumption during these times contribute, in part, to the spikes on weekends and holidays. 
Risk of police-attended IPV was highest for women and for non-Hispanic Blacks and Hispanics in the city that was studied. Three fourths of the assaults of women and two thirds of the assaults of men had the potential to cause injury. However, injuries were observed in only $11 \%$ of the incidents involving female victims and $23 \%$ of those involving male victims, perhaps, due to the nature of assaults. Consistent with previous research using police data (Melton and Belknap 2003), men were more likely than women to experience assaults with external objects and acts that require relatively limited physical strength (e.g., biting, scratching) but that are likely to leave visible marks. This could be because women were more likely than men to use external objects against a partner, perhaps, at least in part, to compensate for their smaller size and lesser physical strength (Felson 1996).

Women, on the other hand, were more likely than men to be assaulted with violent acts that required more physical strength (e.g., punching, kicking, knocking to the ground, arm twisting), and with multiple types of assaults. Consistent with previous research, women were more likely than men to be strangled (Melton and Belknap 2003), and threatened to be killed (Melton and Belknap 2003; Tjaden and Thoennes 2000), both of which are risk markers for lethality that have been shown to increase the odds of homicide five times or more over non-fatal IPV (Campbell et al. 2003; Glass et al. 2008). Strangulation, in particular, is pernicious because, although potentially lethal, it typically leaves no immediate injuries or marks (Strack, McClane, and Hawley 2001). Also, it is believed that some male abusers inflict injuries on women's body parts that either are not easily observed or that are typically covered by clothes (e.g., chest, abdomen, scalp) (Goodman 2006; Sanderson 2008); such assaults can easily escape detection by police officers.

Alternatively, the assumption that women call police when they are in grave physical 
danger may not be how the women actually use the services. Prior research documents that calling the police is associated with a history of being assaulted by the same partner (Abel and Suh 1987; Berk, Berk, and Newton 1984; Brookoff et al.1997). For some, the abuse is frequent: in a survey of 136 female IPV victims at the scene of police calls, 35\% reported being assaulted daily by the same assailant (Brookoff et al.1997). Thus, some likely call police for help not just when they are injured but also when they want the on-going abuse to be interrupted, or in an attempt to muster some amount of control over the situation (Johnson 2007).

Female IPV victims generally seek restraining (protection from abuse) and other court orders if they are experiencing severe violence (Carlson, Harris, and Holden 1999; Keilitz et al. 1998; Zoellner et al. 2000). Such orders are an important secondary prevention mechanism that, have been associated with lower rates of repeat violence (Holt et al. 2002; McFarlane et al. 2004). In the present investigation, very few incidents (about 1\%) resulted in a separate charge of the violation of a restraining order, temporary restraining order or other court order. A general, domestic violence charge also could be used to indicate the violation of temporary restraining orders; thus, an accurate estimate of restraining order violations cannot be made with these data.

Given that as many as $40 \%$ to $60 \%$ of restraining orders are violated (McFarlane et al. 2004; Tjaden and Thoennes 2000), and nearly 25000 restraining orders were estimated to be active in the city during the study period (Sorenson and Shen 2005), one would expect more incidents to have merited such a charge. Perhaps persons to be protected by a restraining order do not call police when the order is violated, police are not likely to respond to calls about restraining order violations, or police do not document the violation as a single stand-alone charge or give priority to documenting other abusive or assaultive behaviors.

Intimate partner violence victims who call the police are more likely to have experienced 
severe physical violence (Bonomi et al. 2006; Davies, Block,and Campbell 2007; Kantor, and Straus 1999), psychological abuse (Bonomi 2006), or injury (Bachman and Coker 1995; Bonomi 2006). And, the findings reported herein highlight the severity of violence experienced by women and the injury potential of police-attended IPV. In addition, prior research documents that, if physical violence is noted in a police or court identified IPV incident, there is a high risk that the victim will be injured by the partner in the subsequent nine months (Crandall et al. 2004). Therefore, it may not be a surprise that about two-thirds of female IPV victims who seek police help are also likely to use emergency health care services at least once in the same year (Kothari and Rhodes 2006). Efforts to establish or strengthen collaboration between law enforcement and health care systems and between these systems and agencies that work with IPV victims (e.g, shelter services, legal services, counseling services, and advocacy groups) may help reduce the violence and injuries experienced by victims.

\section{Using Law Enforcement Data for Public Health Surveillance}

Public health is largely ecumenical in its use of data, particularly administrative data that are available both locally and nationally, as is the case with law enforcement data. Local law enforcement agencies, including the study agency, voluntarily send incident information to the FBI's Uniform Crime Reports (UCR) (93\% of the U.S. population is covered by the participating agencies) (Federal Bureau of Investigation n.d.), and national estimates of IPV are drawn from the compiled data. The UCR uses a hierarchical classification (e.g., if both a rape and an assault with a deadly weapon occur, only the rape is recorded) (Federal Bureau of Investigation 2004), which results in the truncation of the full scope of the phenomenon of IPV, and by extension, our understanding of it. Moreover, if law enforcement agencies do not take into consideration the 
intimate relationship of the victim and suspect in crimes other than physical assault (e.g., threats to kill, vandalism), the nature and scope of IPV is further underestimated. About $9 \%$ ( $\mathrm{n}=836$ ) of the total IPV incidents in the Compstat data were not included in the spousal/cohabitant assaults category and were identified separately from a variety of crimes involving spouses or cohabitants. Therefore, when using law enforcement data for IPV surveillance, it is important to examine all crimes, not just those charged or flagged as IPV-related assaults (Saltzman, Mercy, and Rhodes 1992).

In addition, efforts to understand risk disparities are hampered by the lack of systematic use of an ethnic identifier for Hispanics, the largest minority ethnic group in the nation (U.S. Census Bureau). Neither fatal nor nonfatal assault records in UCR contain a Hispanic identifier despite the passage, over 30 years ago, of the Roybal Act which mandated such an identifier.

The UCR data collection practice of not focusing on information about the victim-suspect relationship in non-fatal incidents (Saltzman, Mercy, and Rhodes 1992; Thompson, Saltzman, and Bibel 1999) is detrimental to our understanding of IPV. Women's risk of IPV is highest during adolescence and young adulthood (prior to the typical marriage age) (Rennison and Welchans 2000), but, as in the UCR, the Compstat data contained no codes for boyfriend, girlfriend or ex-boyfriend/girlfriend, which prevents the complete enumeration of IPV incidents. The absence of such codes virtually assures that IPV in same-sex couples will not be tallied. Even when an incident was flagged as a simple or aggravated assault by a spouse or cohabitant, the specific victim-suspect relationship was not documented in almost $63 \%$ of the cases. Therefore, our count of IPV incidents is most certainly an underestimate of the police-attended IPV cases involving opposite-sex adult couples. It is, therefore, important for communities intending to use law enforcement data for IPV surveillance, to routinely record detailed 
information on the victim-suspect relationship for each incident that comes to their notice (Saltzman, Mercy, and Rhodes 1992).

Large amounts of missing data, as were found with some data fields in this study, present a serious obstacle to using police data for public health surveillance. Complete and accurate records and detailed information on the magnitude and nature of IPV is essential for effective surveillance of IPV. A reliable surveillance system, in turn, can be useful in the development of relevant policy responses to address IPV (Biroscak, Smith, and Post 2006).

\section{Limitations}

This study used police incident reports, an often ignored official data source about IPV (Melton and Belknap 2003). Police often are the first to respond to IPV incidents, and their reports provide valuable on-the-scene information that is unavailable from surveys of community residents or victims who seek medical care or shelter services. Moreover, the law enforcement data system used herein has been adopted by many metropolitan areas, which makes it a useful data source in multiple locales.

Nonetheless, this study is subject to several limitations. First, because it relies on data intended for administrative purposes, variables that might be of interest to researchers and advocates were not always available. Second, our findings were dependent upon police officers filling out the incident reports accurately. It was not possible to ascertain who the source of information was, and, depending upon the source; unknown biases may have been introduced in the recorded information. Third, we were limited by the information the police completed and collected. Data on assaultive behaviors was missing for two-fifth of the incidents involving female victims and a little over two-fifth of the incidents involving male victims. In addition, 
narratives were missing for a quarter of the incidents, and details on victim-suspect relationship were missing for more than one half of the incidents. More complete data on assaultive behaviors would have provided a more complete picture of the nature of IPV victimization. In addition, more information on victim-suspect relationship would have helped analyze differences in victimization across relationship types, and, perhaps, also would have resulted in a higher count of IPV-related incidents in the database. And, finally, given that we had data from one large U.S. city and that many of the findings are consistent with prior research and common knowledge among experienced police officers, analyses using the Compstat systems of other cities would help address questions of external validity.

\section{Implications}

The police typically are one of the first and most common responders to IPV victims (Coulter et al. 1999), and many calls for assistance are received each day. Given the frequency of interaction between law enforcement officers and IPV victims, adequate training of officers (e.g., the dynamics of IPV, local resources such as battered women's shelters and counseling services) is crucial (Townsend et al. 2006). Local advocacy groups often are involved in such trainings, which can strengthen ties between agencies and improve services to victims. Written departmental policies (e.g., how to respond to IPV cases, requirements related to completion of incident reports and other supplemental forms specific to IPV cases) also are needed to improve service to victims and documentation of IPV in the community (Klein 2009).

Compstat systems can identify crime patterns that can aid in law enforcement management decisions. For example, many IPV incidents occurred during evenings, nights, and early morning hours as well as on weekends and certain holidays, times when many departments 
already deploy more officers (Cohn 1993). Additional collaboration with victim advocates or trained volunteers may be needed during these high frequency periods (Klein 2009).

Law enforcement is a key portal to resources for IPV victims in many communities. When police offer active assistance to victims, that is, provide information about shelters and self-protection, ask about injuries and need for medical care, IPV victims may feel safer or may feel satisfied and be more likely to call for assistance again (Johnson 2007). Furthermore, information about police contacts may be useful for medical intervention: asking female emergency department patients about IPV- related calls to police has been shown to increase IPV detection by 30 percent (Dichter and Rhodes 2009). Therefore, greater collaboration between law enforcement agencies, health care providers, advocacy groups, and service agencies is essential in efforts to reduce and prevent IPV (Davies, Block, and Campbell 2007).

Women seek restraining orders most often when they experience severe violence (Carlson, Harris, and Holden 1999; Keilitz et al. 1998; Zoellner et al. 2000), or when their family members or friends also are assaulted by the abuser (Wolf et al. 2000). In addition, restraining orders typically are sought and obtained when the victim is either trying to separate or has separated from her abuser, a particularly high risk period for homicide (Wilson, Daly, and Wright 1993). Moreover, persons under certain domestic violence restraining orders are prohibited by federal law from purchasing and possessing a firearm, which has clear implications for the prevention of lethal violence. Therefore, in the city we studied, it appears that law enforcement needs to play a more active role in restraining order violations. The abuser's violation of the order should be treated and documented as a separate crime, and officers should always ask an IPV victim if the suspect used or has a firearm. Whether this pattern of far fewer than expected restraining order violations holds in other locales remains to be seen. 
Given the frequency with which abused persons turn to police, law enforcement data may be a useful tool for public health surveillance of IPV. However, the data will be more useful if they are more complete, provide for the easy identification of incidents involving not just spouses and cohabitants but a more complete range of current and former intimate pairings, and consistently employ a Hispanic identifier so as to accurately identify groups at particular risk. The latter is particularly important in the analysis of Compstat data: most Hispanics in the U.S. nearly $90 \%$ by some estimates - reside in metropolitan areas.

In closing, the repetitive nature of IPV - the same victim is assaulted repeatedly by the same assailant - merits consideration. If law enforcement practices used for discrete incidents are applied to frequent abuse that results either in no observable injuries or injuries that are considered minor, a normalization of sorts may occur (Stark 2007). If police and other emergency personnel intervene only in the most violent incidents, the average level of abuse perceived as acceptable may rise. Thus, intervening appropriately in "low level" incidents may reduce subsequent fatal and non-fatal abuse. 


\section{References}

Abel, E. M., and E. K. Suh. 1987. Use of police services by battered women. Social Work $32: 526-8$.

Bachman, R., and A. L. Coker. 1995. Police involvement in domestic violence: Interactive effects of victim injury, offender's history of violence and race. Violence and Victims 10:91-106.

Bachman, R., and L. E. Saltzman. 1995. Violence against women: Estimates from the redesigned survey. Washington, DC: U.S. Department of Justice, Bureau of Justice Statistics.

Berk, R.A., S. F. Berk, P. J. Newton, and D. R. Loseke.1984. Cops on call: summoning the police to the scene of spousal violence. Law \& Society Review 18:479-98.

Biroscak, B. J., P. K. Smith, and L. A. Post. 2006. A practical approach to public health surveillance of violent deaths related to intimate partner relationships. Public Health Reports 121:393-99.

Bonomi, A. E., V. L. Holt, D. Martin, and R. S. Thompson. 2006. Severity of intimate partner violence and occurrence and frequency of police calls. Journal of Interpersonal Violence $21: 1354-64$.

Bratton, W. J., and S. W. Malinowski. 2008. Police performance management in practice: Taking Compstat to the next level. Policing 2:259-65.

Brookoff, D., K. K. O’Brien, C. S. Cook, T. D. Thompson, and C. Williams. 1997. Characteristics of participants in domestic violence: Assessment at the scene of domestic assault. Journal of American Medical Association 277:1369-73.

Campbell J. C., D. Webster, J. Koziol-McLain, C. Block, D. Campbell, M. A. Curry, F. Gary, et al. 2003. Risk factors for femicide in abusive relationships: Results from a multisite case 
control study. American Journal of Public Health 93:1089-97.

Carlson, M. J., S. D. Harris, and G. W. Holden. 1999. Protective orders and domestic violence: risk factors for re-abuse. Journal of Family Violence 14:205-26.

Catalano, S. 2006. Intimate partner violence in the United States. Washington, DC: U.S. Department of Justice.

Chaudhuri, M., and K. Daly. 1992. Do restraining orders help? Battered women's experience with male violence and legal process. In Domestic violence: The changing criminal justice response, edited by E. S. Buzawa and C. G. Buzawa, 227-52. Westport, CT: Auburn House.

Cohn, E. G. The prediction of police calls for service: The influence of weather and temporal variables on rape and domestic violence. 1993. Journal of Environmental Psychology $13: 71-83$.

Coulter, M. L., K. Kuehnle, R. Byers, and M. Alfonso. 1999. Police-reported behavior and victim-police interactions as described by women in a domestic violence shelter. Journal of Interpersonal Violence 14:1290-98.

Crandall, M. L., A. B. Nathens, M. A. Kernic, V. L. Holt, and F. P. Rivara. 2004. Predicting future injury among women in abusive relationships. The Journal of Trauma 56:906-12.

Davies, K., R. C. Block, and J. Campbell. 2007. Seeking help from the police: Battered women's decisions and experiences. Criminal Justice Studies 20:15-41.

Dichter, M., and K. V. Rhodes. 2009. Reports of police calls for service as a risk indicator of intimate partner violence. Academic Emergency Medicine 16:83-6.

Federal Bureau of Investigation, U. S. Department of Justice. 2004. Uniform Crime Reporting Handbook. http://www.fbi.gov/ucr/handbook/ucrhandbook04.pdf. (accessed July 15, 
2008).

Federal Bureau of Investigation, U.S. Department of Justice. Uniform Crime Reporting (UCR) Summary Reporting. http://www.fbi.gov/ucr/ucrquest.htm (accessed July 15, 2008).

Felson, R. B. 1996. Big people hit little people: Sex differences in physical power and interpersonal violence. Criminology 34:433-52.

Friday, P., V. Lord, M. Exum, and J. Hartman. 2006. Evaluating the impact of a specialized domestic violence police unit. NCJ 215916. Washington, DC: U.S. Department of Justice, National Institute of Justice.

Glass, N., K. Laughon, J. Campbell, C. R. Block, G. Hanson, P. W. Sharps, and E. Taliaferro. 2008. Non-fatal strangulation is an important risk factor for homicide of women. Journal of Emergency Medicine 35:329-35.

Goodman, P. E. 2006. The relationship between intimate partner violence and other forms of family and societal violence. Emergency Medicine Clinics of North America 24:889-903.

Holt, V. L., M. A. Kernic, T. Lumley, M. E. Wolf, and F. P. Rivara. 2002. Civil protection orders and risk of subsequent police-reported violence. Journal of American Medical Association 288:589-94.

Houry, D., C. Parramore, G. Fayard, J. Thorn, S. Heron, and A. Kellerman. 2004. Characteristics of household addresses that repeatedly contact 911 to report intimate partner violence. Academic Emergency Medicine 11:662-67.

Hutchison, I. W., and J. D. Hirschel. 1998. Abused women: help-seeking strategies and police utilization. Violence Against Women 14:436-56.

Johnson, I. M. 2007. Victims' perceptions of police response to domestic violence incidents. Journal of Criminal Justice 35:498-510. 
Kantor, G. K., and M. A. Straus. 1999. Response of victims and the police to assault on wives. In Physical violence in American families: Risk factors and adaptations to violence in 8,145 Families, edited by M. A. Straus and R. J. Gelles, 473-87. New Brunswick, NJ: Transaction.

Keilitz, S. L., C. Davis, H. S. Efkeman, C. Flango, P. L. Hannaford. 1998. Civil protection orders: Victims’ views on effectiveness. FS 000191. Washington, DC: U.S. Department of Justice.

Klein, A. R. 2009. Practical implications of current domestic violence research: For law enforcement, prosecutors and judges. NCJ 225722. Washington, DC: U.S. Department of Justice.

Kothari, C. L., and K. V. Rhodes. Missed opportunities: Emergency department visits by policeidentified victims of intimate partner violence. Annals of Emergency Medicine 47:190-99.

McFarlane, J., A. Malecha, J. Gist, K. Watson, E. Batten, I. Hall, and S. Smith. 2004. Protection orders and intimate partner violence: an 18-month study of 150 Black, Hispanic, and White women. American Journal of Public Health 94:613-8.

Melton, H. C., and Belknap, J. 2003. He hits, she hits: Assessing gender differences and similarities in officially reported intimate partner violence. Criminal Justice and Behavior 30:328-48.

Philadelphia Police Department. The Compstat process. http://www.ppdonline.org/hq_compstat.php (accessed October 31, 2009).

Rennison, C. M., and S. Welchans. 2000. Intimate partner violence. NCJ 178247. Washington, DC: U.S. Department of Justice, Bureau of Justice Statistics.

Rotton, J., and J. Frey. 1985. Air pollution, weather and violent crimes: Concomitant time-series 
analysis of archival data. Journal of Personality and Social Psychology 49:1207-20.

Saltzman, L. E., J. A. Mercy, and P. H. Rhodes. 1992. Identification of nonfatal family and intimate assault incidents in police data. American Journal of Public Health 82:1018-20.

Sanderson, C. 2008. Counseling survivors of domestic abuse. London, UK: Jessica Kingsley Publishers.

Shane, J. M. 2004. Compstat process. FBI Law Enforcement Bulletin 73:12-21.

Shepherd, J. 1990. Violent crime in Bristol: An accident and emergency room perspective. British Journal of Criminology 30:289-305.

Sorenson, S. B., and H. Shen. 2005. Restraining orders in California: A look at statewide data. Violence Against Women 11:912-33.

Stark, E. 2007. Coercive control: how men entrap women in personal life. New York, NY: Oxford University Press.

Strack, G. B., G. E. McClane, and D. Hawley. 2001. A review of 300 attempted strangulation cases: Criminal legal issues. Journal of Emergency Medicine 21:303-9.

Straus, M. A., and R. J. Gelles.1999. How violent are American families? Estimates from the National Family Violence Resurvey and other studies. In Physical violence in American families: Risk factors and adaptations to violence in 8,145 Families, edited by M. A. Straus and R. J. Gelles, 95-112. New Brunswick, NJ: Transaction.

Thompson, M. P., L. E. Saltzman, and D. Bibel. 1999. Applying NIBRS data to the study of intimate partner violence: Massachusetts as a case study. Journal of Quantitative Criminology 15:163-80.

Tjaden, P., and N. Thoennes. 2000. Extent, nature, and consequences of intimate partner violence: Findings from the National Violence Against Women Survey. NCJ 181867. 
Washington, DC: U.S. Department of Justice, National Institute of Justice, and Centers for Disease Control and Prevention.

Townsend, M., D. Hunt, S. Kuck, and C. Baxter. 2006. Law enforcement response to domestic violence calls for service. NCJ 215915. Washington, DC: U.S. Department of Justice.

U.S. Census Bureau. 2005 American Community Survey, Detailed Tables. http://factfinder.census.gov/servlet/DTGeoSearchByListServlet?ds_name=ACS_2005_E $\underline{\text { ST_G00_\&_lang=en\&_ts=248709160339 }}$ (accessed July 15, 2008).

U.S. Census Bureau. State \& County Quickfacts: USA. http://quickfacts.census.gov/qfd/states/00000.html (accessed July 20, 2008).

Willis, J. J., S. D. Mastrofski, and D. Weisburd. 2003. Compstat in practice: An in-depth analysis of three cities. Police Foundation.

Willis, J. J., S. D. Mastrofski, and D. Weisburd. 2007. Making sense of COMPSTAT: a theorybased analysis of organizational change in three police departments. Law \& Society Review 41:147-88.

Wilson, M., M. Daly, and C. Wright. Uxoricide in Canada: Demographic risk patterns. Canadian Journal of Criminology 35:263-91.

Wolf, M. E., V. K. Holt, M. A. Kernic, and F. P. Rivara. 2000. Who gets protection orders for intimate partner violence? American Journal of Preventive Medicine 19:286-91.

Zoellner, L. A., N. C. Feeny, J. Alvarez, C. Watlington, M. L. O’Neill, R. Zagner, and E. B. Foa. 2000. Factors associated with completion of the restraining order process in female victims of partner violence. Journal of Interpersonal Violence 15:1081-99. 
Table 1. Couple characteristics, police-attended opposite-sex intimate partner violence, $\%$

$\begin{array}{cc}\text { Male-on-female } & \text { Female-on-male } \\ \text { violence } & \text { violence } \\ (\mathrm{n}=7897) & (\mathrm{n}=1334)\end{array}$

Total

85.6

14.5

Race/Ethnicity

Hispanic-Hispanic

52.7

40.4

Black-Black

22.1

21.4

White-White

8.6

15.1

Asian Pacific Islander-Asian Pacific Islander

0.4

0.2

Other

1.8

2.7

Inter-racial/ethnic relationship

14.5

20.2

Age (suspect-victim)

$10+$ years younger

4.2

13.7

5-9 years younger

9.2

17.8

20.6

1-4 years younger

8.9

30.2

Same age

30.7

7.4

1-4 years older

18.3

17.4

5-9 years older

10.8

7.3

$10+$ years older

3.3

Relationship (suspect-victim)

Spouse

24.2

25.4

Boyfriend-girlfriend $^{\mathrm{a}}$

7.0

Involved in the past ${ }^{\mathrm{a}}$

2.7

6.8

Not specified

66.7

2.8

66.0

Cohabiting

Yes

31.3

32.9

Not specified

68.7

67.1

Child together ${ }^{1}$

Yes

8.6

9.8

Not specified

91.4

90.3

Note. Percents do not always total to 100 because of rounding error.

${ }^{\mathrm{a}}$ Variables were created from the report narratives. Narratives were recorded for $73 \%$ of the incidents and the first 80 characters of each narrative were available. 
Table 2. Characteristics of police-attended intimate partner violence incidents, opposite-sex couples, $\%$

$\begin{array}{cc}\text { Male-on-female } & \text { Female-on-male } \\ \text { violence } & \text { violence } \\ (\mathrm{n}=7,897) & (\mathrm{n}=1,334)\end{array}$

Weapon type (used or threatened to be used) ${ }^{\mathrm{a}}$

Hands, feet, fists

Cutting/stabbing instrument (e.g., knives, razors, machetes)

Blunt object (e.g., clubs, boards, bats, sticks)

2.8

8.6

Words (e.g., threats to kill)

2.1

0.7

Firearm

0.8

0.5

Other/unknown (e.g., keys, ashtray, lamp, pepper spray)

3.6

7.1

Nature of assaultive behavior ${ }^{\mathrm{b}}$

Assaultive behaviors with physical injury potential

Slap/hit/strike with body parts

16.3

14.7

Punch

11.6

6.1

Strangle

11.0

1.1

Knock to the ground

9.5

0.9

Push

9.0

2.5

Kick

7.5

3.2

Pull hair

6.9

0.5

Hit with an object

1.9

6.1

Bit

1.9

7.7

Cut/stab

1.5

7.4

Scratch

1.0

14.8

Twist arm

0.5

0.0

Burn

0.2

0.2

Shot

0.0

0.0

Verbal threats

Threaten to kill

4.8

1.1

Threaten to kill family member

0.4

0.1

Intimidation

4.3

2.1

Other assaultive behaviors (e.g., blindfold, cover mouth, handcuff)

Not specified $^{\mathrm{c}}$

38.7

45.5

Characteristics of the assault ${ }^{\mathrm{d}}$

Attacks on the face/head

8.1

Multiple strikes of one type of assault

6.1

4.4

Number of different types of assaults

40.0

37.0

2

15.6

7.6

$3+$

5.3

0.5 
Observed injury ${ }^{\mathrm{d}}$

Yes

Not specified $^{\mathrm{c}}$

Location

Single family dwelling

Multi-unit dwelling (apartment, duplex)

Street/parkway/sidewalk/alley/driveway

Parking lot/park/playground

Hotel

Vehicle

Other (e.g., restaurant, gasoline station, construction trailer)

Initial charge

Mean

Type $^{\mathrm{e}}$

Aggravated assault

Battery misdemeanor

Criminal threats/threat by letter or phone)

Assault with a deadly weapon

Violation of a restraining order, temporary restraining order, or court order

Forcible rape/rape attempt

0.5

0.0

Other (e.g., property crime, petty theft, vandalism)

Case status

Cleared by arrest

Note. Percents do not always total to 100 because of rounding error.

${ }^{a}$ If more than one type of weapon was used in an incident, only the dominant weapon was recorded.

${ }^{\mathrm{b}}$ Percents do not total 100 because more than one type of assaultive act is possible in an incident.

cExpected to include both "no" and not documented.

${ }^{\mathrm{d}}$ These variables were created from the police narratives. Narratives were recorded for $73 \%$ of the incidents and the first 80 characters of each narrative were available.

${ }^{\mathrm{e}}$ Percents do not total 100 because more than one type of charge is possible for each incident. 
Figure 1. Rate of police-attended intimate partner violence in one large U.S. city, estimated annual average, by victim gender and ethnicity, 2005

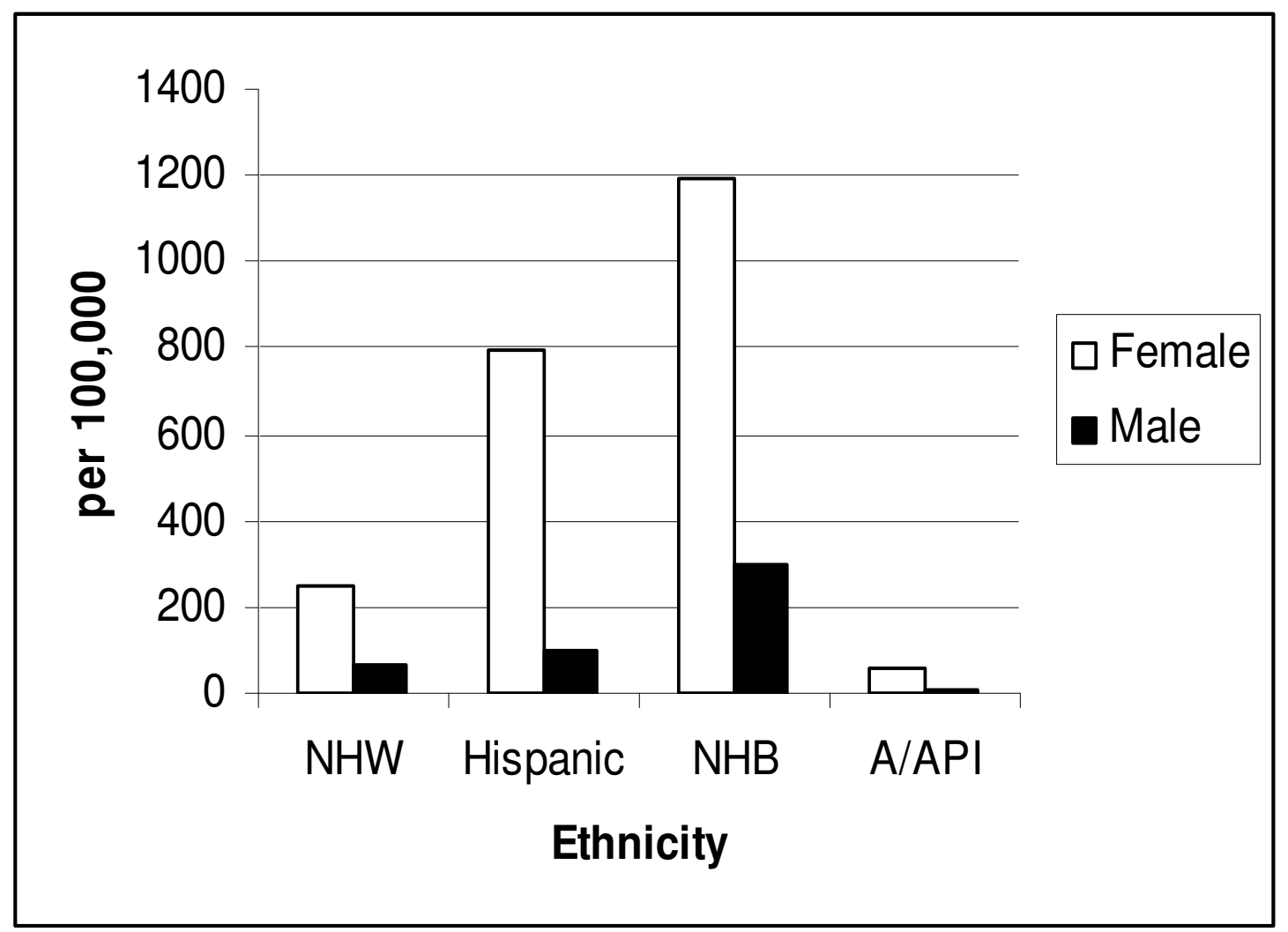

Note. NHW: non-Hispanic White; NHB: non-Hispanic Black; A/API: Asian and Asian Pacific Islander 